\title{
Geography without a prefix
}

The Academy of Finland recently published the yearly review "The state of scientific research in Finland 2012". In the section related to geography, the Geographical Society of Finland was mentioned twice. The review stated that the Society does not dynamically support the development of geography in Finland, and that the Finnish geographical journals, published by the Society, are not indexed in the Web of Science.

Geography is a traditional field of science both internationally and in Finland. The Society and its journals, Fennia and Terra, as well as the National Atlas of Finland, have more than a century long history in disseminating and communicating geographical knowledge and expertise. The role of scientific societies has varied through times and is currently quite marginal.

As the president of the Geographical Society of Finland, I have been able to collect different views and wishes from geographers working in Finland. There seems to be a genuine need to strengthen the role of the Society as a collective voice of geographers promoting geographical research and education in Finland, and making geographical expertise visible in the society.

Two main processes where the Society could take a stronger role to promote geography are the structural reform of universities and the scientific competition and ranking.

The current phrasing of questions related to the multitude of global to local challenges asks for an integrated and multidimensional approach recognising scales and interactions between scales. The current academic research and education seem not to meet these societal needs and are thus urged to change. In this currently on-going reform, each university needs to define distinctive research profiles with a few sharp research fronts. In education thematically wider lower degrees are favoured and interdisciplinary understanding is promoted. Universities are given more flexibility to reorganize and mix traditional scientific fields to fulfil these aims. In many occasions, it seems that geography is invented again in the mushrooming of multidisciplinary study modules and research projects. At the same time, there are pressures to reduce geography into geo-, social or administrative sciences, in which case intrinsic components of the potential of our discipline are at risk.

Along with the structural modernisation, the academic world is internalising the ideal of competitiveness. Competition as such may bring out new innovations and ideas and rationalise the work done in scientific institutions. However, competition can be harmful if favouring economies of scale over viable and dynamic development of science and compromising academic freedom and integrity. In the scientific community, competition is culminated in the ranking of journals, articles and scientists mainly mastered by the Thompson Reuters ISI Web of Knowledge. In Finland, we also have a national ranking system, the Publication Forum Project established by the Federation of Finnish Learned Societies.

Finnish geographical journals have struggled in this competition in spite of their established status in geographical publishing. To be indexed in the web of knowledge or to get into a higher level in the publication forum, journals need to publish top-quality research papers with high number of citations. To scientists and their institutions, it is more beneficial to publish papers in leading journals. Therefore, it is challenging to draw submissions to journals with lower ranking. The situation with Fennia and Terra resembles a classic egg-hen cycle which may have either negative or positive trend. Our journals need more submissions to feed a positive spiral: increased number of submissions - top-quality articles - more readers and citations - higher ranking. The editors and publisher are actively seeking for potential solutions to ensure the positive development. Several possibilities were explored in the Finnish Geography Days in October 2012: joining an international commercial or OAJ publisher, tightening Nordic collaboration, merging of the two Finnish journals, or changing or clarifying the scope and roles of the journals. This multi-voiced discussion is continuing.

To change the two trends - disintegration or even disappearance of geography as a discipline, 
and impoverishment of the geographical publishing, we need to join together to define common goals and to work in cooperation to achieve that goal. The Society is us, and the direction of the change needs to be decided collectively. The actions call for dialogue, ownership, commitment and collaboration.
More information about the visions for the future communication and publishing strategy of the Geographical Society of Finland at www.geography.fi.

Sanna Mäki, President of the Geographical Society of Finland

Geography lecturer, Department of Geography and Geology, University of Turku 